\title{
Vacuolar Protein Sorting
}

National Cancer Institute

\section{Source}

National Cancer Institute. Vacuolar Protein Sorting. NCI Thesaurus. Code C21242.

Vacuolar Protein Sorting consists of subcellular and biochemical mechanisms involving cell membranes that govern the subcellular location of certain membrane-bound or associated proteins. 